\title{
A VIRTÙ E A REGRA: NOTA SOBRE MAQUIAVEL
}

\author{
Luiz Carlos Montans Braga ${ }^{1}$ \\ Pontifícia Universidade Católica de São Paulo (PUCSP) \\ (D) https://orcid.org/0000-0002-6989-1249
}

\section{RESUMO: \\ O artigo pretende tratar de um tema presente nos Discursos sobre a primeira década de Tito Lívio, bem como em outros textos de Maquiavel: o dos homens bons plenos de virtù e seu papel na fundação do campo jurídico-político. A primeira questão a ser trabalhada é a do método em Maquiavel. Após, o conceito de virtù será analisado no que se refere a sua importância para a fundação e manutenção jurídico-política da cidade. \\ PALAVRAS-CHAVE: Virtù; Regra; Maquiavel. \\ THE VIRTU் AND THE RULE: NOTE ON MACHIAVELLI}

\begin{abstract}
:
The article intends to deal with a theme present in Discourses on the first decade of Titus Livius, as well as in other Machiavelli texts. The theme is the good man full of virtù and its role in the foundation of the legal-political field. The first issue is the method in Machiavelli. After, the concept of virtù will be analyzed in terms of its importance for the establishment and maintenance of legal-political field in the city.
\end{abstract}

KEYWORDS: Virtù; Rule; Machiavelli.

\section{Tateando as questões}

Qualquer tentativa de fixar estacas na obra de Maquiavel é trabalho árduo. Trata-se de obra movediça. $\mathrm{O}$ texto é simultaneamente claro e sinuoso. Claro em razão do estilo límpido do florentino, com o uso de capítulos curtos e escrita que trata, em geral, diretamente dos temas que dão

\footnotetext{
${ }^{1}$ Doutor em Filosofia pela Pontifícia Universidade Católica de São Paulo (PUC/ SP), São Paulo - Brasil. E-mail: montansbraga@ hotmail.com
} 
nome aos capítulos ${ }^{2}$. Tome-se como exemplo $O$ Príncipe, cujos capítulos não chegam, algumas vezes, a meia página ${ }^{3}$. Sinuoso em razão de sua vasta erudição e dos raciocínios ao mesmo tempo certeiros, densos e impactantes, os quais vão se desdobrando em uma miríade de cenários a partir da análise dos fatos históricos. A estabilidade, portanto, para o leitor, sobretudo o contemporâneo, é precária. Daí o uso de termos como enigma para qualificar a obra ou a razão pela qual Maquiavel seria "o fundador da moderna visão da política" (BIGNOTTO, 2003: 114).

Em razão da potência analítica dos textos, o enigma Maquiavel rendeu frutos, vários, na história da filosofia e em outras áreas do conhecimento. Isaiah Berlin (BERLIN, 2002: 299) chega a afirmar que

há algo de surpreendente sobre o número de interpretações das opiniões políticas de Maquiavel. Existem, mesmo agora [1972], mais de vinte teorias principais de como interpretar $O$ príncipe e os Discursos - à parte a enorme quantidade de visões e explicações subsidiárias.

Eis o terreno em que se move aquele que pretende escrever sobre a obra do florentino. Pode-se afirmar, com razoável grau de certeza, que quem pretende escrever sobre a filosofia política de Maquiavel deve fazê-lo em forma de ensaio. E isto no sentido mais forte do termo cunhado por Montaigne: tentativa de compreensão sem pretensões de totalização ou esgotamento do assunto. E, corolário, muitas camadas de comentários que divergem entre si devem ser observadas sempre à luz do texto-fonte: a obra de Maquiavel como texto primário de referência.

Este artigo, em forma de breve ensaio, pretende lançar luz sobre um tema menos palmilhado pelos comentadores, presente nos Discursos sobre a primeira década de Tito Lívio, bem como em outros textos de Maquiavel: o dos homens bons plenos de virtù, os quais fundam campos político-jurídicos ou os transformam com vistas à estabilidade perdida. Para tal tarefa, serão focadas passagens do livro terceiro dos Discursos, bem como algumas d' $O$ príncipe. E, ainda, haverá uma introdução sobre a virada metodológica do florentino. Por outra, as seguintes questões serão analisadas a partir do tema

\footnotetext{
2 Trata-se de escrita clara também do ponto de vista da comparação com autores como Hegel ou Kant, para ficar em dois exemplos de autores da história da filosofia que apresentam textos simultaneamente complexos na sintaxe, densos nas temáticas e de argumentação longa.

${ }^{3}$ Quanto a $O$ Príncipe, o capítulo 1 ocupa meia página; o 2, dois terços de página. E há bastantes outros capítulos curtos, claros e densos em conceitos. Tome-se por exemplo o capítulo XV da referida obra, que, na hipótese deste ensaio, define o método de Maquiavel - nada mais nada menos. Ele possui página e meia (MAQUIAVEL, P, XV: 151-153 da edição bilíngue ora utilizada).
} 
central $^{4}$ : o que há de novo no proceder maquiaveliano no que se refere à maneira de fazer filosofia política? Por que o autor dá ênfase especial a certos tipos de homem na fundação, manutenção e refundação dos corpos políticos? Por que tais homens recebem a qualidade de bons? O que significa, para Maquiavel, no campo político, ser homem bom? Em que medida o florentino se distancia do gênero literário dos espelhos dos príncipes (SKINNER, 2009: 149) ${ }^{5}$ para identificar o que é bom no campo político? E, por fim, o que significa, para Maquiavel, ser pleno de virtù? Esta última questão implica a análise do conceito de virtù, termo fundamental no pensamento político do autor e objeto de interpretações diversas, segundo Aranovich (ARANOVICH, 2007: 457-471). Virtù, ou seja, vis, força ou potência, como uma espécie de cunha que fissura o campo político e instaura o novo ordenamento (novas leis), fundando ou reavendo a estabilidade da cidade. Há, pois, um quê de jurídico no conceito. Entretanto, não como estrito dever-ser, mas como força que instaura o regramento novo, o qual se sustenta por um novo rearranjo de forças em disputa.

Maquiavel tinha consciência da alta voltagem de seus escritos tratava-se de um rompimento em face do que havia na seara da análise do fenômeno político. Sabia, também, dos riscos do empreendimento. No "Proêmio" do Livro Primeiro dos Discursos, Maquiavel afirma que o caminho que pretende trilhar não fora trilhado por ninguém até então, e compara seu empreendimento ao da procura de águas e terras desconhecidas. Com efeito, afirma o autor, no estilo retórico do Proêmio:

Ainda que, devido à natureza invejosa dos homens, sempre tenha sido tão perigoso encontrar modos e ordenações novos quanto procurar águas e terras desconhecidas - por estarem os homens sempre mais prontos a censurar do que a louvar as ações alheias -, assim mesmo, levado pelo natural desejo que em mim sempre houve de trabalhar, sem nenhuma hesitação, pelas coisas que me pareçam trazer benefícios comuns a todos, deliberei entrar por um caminho que, não tendo sido ainda trilhado por ninguém, se me trouxer enfados e dificuldades, também me poderá trazer alguma recompensa, por meio daqueles que considerarem com humanidade os objetivos deste meu labor. (MAQUIAVEL, D, I, "Proêmio": 05) 6 .

\footnotetext{
${ }^{4}$ As análises acerca dessas questões estão difusas nos tópicos seguintes: "O 'método' maquiaveliano" e "Os homens bons, segundo Maquiavel: plenos de virtù".

5 Para Skinner, em suma, Maquiavel estaria na chave dos espelhos e, ao mesmo tempo, criticaria muitos de seus termos-chave. Por exemplo, o da educação do príncipe pela moral cristã. Conferir, também, BIGNOTTO, Newton. A antropologia negativa de Maquiavel. In: Analytica. Vol. 12. N.2. Rio de Janeiro: 2008, pp. 77-100, especialmente pp. 80-81.

${ }^{6}$ Para facilidade de consulta a outras edições, quando a citação for de Maquiavel, usa-se D para os Discorsi e P para O Príncipe. Em D, logo após, em numerais romanos, tem-se o Livro, e, a seguir, em arábico, o Capítulo, com exceção do Proêmio, que será anunciado como tal. Logo depois, o número da página da edição consultada. Em P, cita-se o capítulo
} 
O recorte a ser feito na obra do florentino intenta, pois, analisar a questão dos homens bons não como os que cumprem as regras jurídicas ou morais, que seguem modelos prévios, religiosos ou jurídicos, utopias de cidade, mas como aqueles plenos de virtù, ou seja, detentores de força ou potência que fissura o real sem a utilização de modelos prévios. Tal movimento argumentativo será feito à luz da inovação maquiaveliana no campo da análise do político, uma hipótese que aqui levanto, ou seja, à luz de seu novo "método".

A hipótese do método, que explicito e desenvolvo no item a seguir, está de acordo com a tese presente no excerto acima, retirado dos Discursos, a saber, a de que Maquiavel procurou o novo na filosofia política tal qual aquele que se arrisca em águas e terras nunca antes frequentadas.

\section{0 "método" maquiaveliano"}

Maquiavel, no capítulo XV d'O príncipe (MAQUIAVEL, P, XV: 151-153), oferece ao seu leitor o que se poderia chamar de "método" assim, entre aspas ${ }^{8}$. O que há de novo no proceder maquiaveliano? O capítulo se intitula "Das coisas pelas quais os homens, e especialmente os príncipes, são louvados ou vituperados". Nele, o autor pretende tratar dos modos e atos de governo de um príncipe em face dos súditos e dos amigos. Para isso, afirma, "afasto-me do modo de raciocinar dos outros". Em decorrência, escreve: "pareceu-me mais convincente ir direto à verdade efetiva da coisa do que à imaginação dessa. E muitos imaginaram repúblicas e principados que nunca foram vistos, nem conhecidos de verdade." (MAQUIAVEL, P, XV: 151).

\footnotetext{
em romanos e a seguir o número da página da edição consultada. As edições consultadas estão ao final, na referência bibliográfica.

${ }^{7}$ Para melhor compreender a abordagem maquiaveliana do tema dos "homens bons como aqueles plenos de virtù", talvez seja importante tratar, antes, da virada metodológica proposta pelo autor. Ou seja, da passagem de uma filosofia política do dever ser (plano do jurídico e da moral, bem como das utopias pensadas como modelos a serem instalados) para uma filosofia política do ser. Isto talvez dê mais consistência e clareza aos argumentos inovadores de Maquiavel acerca do tema dos "homens bons plenos de virtù".

${ }^{8}$ Conforme hipótese levantada pelo professor Antonio José Romera Valverde, em aula do curso Liberdade política e natureza humana, ministrado aos alunos da pós-graduação em filosofia da PUC-SP (1\%/2012) - aula do dia 17 de maio de 2012. A hipótese é: Maquiavel não escreveu uma obra ou um texto sobre seu método. No entanto, apresenta, sobretudo em um momento de sua obra, certo modo de fazer filosofia política que pode ser entendido como "método". Um método em tudo novo, cujo uso implica, entre outras coisas, a descoberta e o desenvolvimento do importante tema dos homens bons como detentores de virtù.
}

A virtù e a regra: nota sobre Maquiavel - Luiz Carlos Montans Braga 
Ou seja, o florentino pretende fazer filosofia política, ou antropologia política ${ }^{9}$, tendo como fundamento não o dever ser dos corpos políticos, mas o ser desses objetos. Por conseguinte, ir à verdade efetiva da coisa é deixar de lado aquilo que se deseja sobre a melhor organização política de um principado ou de uma república para, em vez disso, compreender o que de fato é necessário para tal ou qual corpo político se fundar e se manter ${ }^{10}$. Portanto, o chão, isto é, o fundamento da análise proposta por Maquiavel é o ser efetivo dos corpos políticos, sua concretude ou materialidade, e não a descrição de um corpo político imaginado, com suas regras jurídicas, seu dever-ser, a ser alcançado pela ação humana virtuosa. Ação humana virtuosa, isto é, aquela cumpridora das regras previamente estabelecidas, morais ou jurídicas.

Nesse ponto, pois, explicita-se um traço fundante do método maquiaveliano: em vez de descrições utópicas ou da confecção de modelos a serem perseguidos, escreve o autor que "pareceu-me mais convincente ir direto à verdade efetiva da coisa do que à imaginação dessa [mi è parso più conveniente andare drieto alla verità effettuale della cosa che alla immaginazione di epsa]" (MAQUIAVEL, P, XV: 150-151).

Portanto, a ruptura maquiaveliana tem como alvo o método de análise do político e do jurídico como utopias, isto é, arquiteturas políticas imaginadas. Tese presente, como exemplo eloquente do contraponto a Maquiavel, em Thomas More, na Utopia. A expressão 'utopia' foi cunhada por More ao fundir o advérbio grego ou (não), ao substantivo topos (lugar). No relato fictício da obra, o 'não-lugar' de More é uma ilha recém descoberta, cujo local é alguma parte do Novo Mundo. E o título completo do livro, "Sobre a melhor constituição de uma república e a nova ilha de Utopia", atesta o sentido que o termo utopia veio a adquirir: uma sociedade perfeita ou sua descrição literária (LOGAN, 2003: xi). De fato, em lugar da realidade efetiva da coisa, como é o caso da matéria prima maquiaveliana, o que há nesta obra de Thomas More está bem explicitado no título completo da Utopia (MORE, 1993; MORE, 2003).

Em Maquiavel, pois, a filosofia política da descrição do imaginado dá lugar à filosofia política que decorre da análise da prática política.

E a prática política tem como fonte, sobretudo, o exemplo dos antigos, especialmente o de Roma. Entretanto, um cuidado, ainda metodológico, deve ser tomado. Não há história ou prática política passada

\footnotetext{
${ }^{9}$ Conferir VALVERDE, A.J.R..Maquiavel: a natureza humana e o reino deste mundo. In: SGANZERLA, Anor; FALABRETTI, Ericson; VALVERDE, Antonio José Romera (orgs.). Natureza humana em movimento: ensaios de antropologia filosófica. São Paulo: Paulus, 2012, pp. 51-61. Escreve o autor: "Maquiavel não funda, propriamente, uma antropologia filosófica. Mas, pelas assertivas, contidas em sua obra, acerca da natureza e da condição histórica humanas, (...) constrói, no limite, uma antropologia política” (p. 51).

${ }^{10}$ Sobre o tema da veritá effetuale, ver o ensaio de: LEFORT, Claude. Maquiavel e a veritá effetuale. In: Desafios da Escrita Política. Tradução de Eliana de Melo Souza. São Paulo: Discurso editorial, 1999, pp. 141-177.
} 
ou presente que não tenha que passar pelo crivo da boa análise, sem o quê seria fato bruto, destituído de qualquer serventia para uma antropologia política. Claude Lefort lembra, sobre esta questão, com a habitual agudeza:

Elogio da Antiguidade, apelo à imitação, passagem obrigatória pela leitura de um grande autor: por certo, tal é precisamente o tema de abertura de Os discursos. Porém, nem o passado, sobretudo o passado romano, nem o texto que guia o acesso a eles, o texto de Tito Lívio, revelam-se suscetíveis de um conhecimento imediato; requerem decifração; seu significado mostra-se somente para aqueles que sabem compreender os fatos por meio do livro e o livro por meio dos fatos, e mesclar os fatos presentes e passados. (LEFORT, 1999: 143).

Roma, assim, é a fonte factual por excelência. É dela, sobretudo, que Maquiavel retira os fatos históricos que possibilitarão, por meio de certo método indutivo, a confecção de algumas máximas no campo da política. $\mathrm{E}$ por que Roma? Uma hipótese é a de que Roma permaneceu muito tempo como corpo político, fazendo as modificações necessárias para sua não dissolução. Outra, apontada por Lefort, não excludente da anterior, se apresenta em uma proposição acerca da relação de Maquiavel com os antigos:

Os antigos são superiores aos modernos porque estes são vítimas da ética cristã que os proíbe de buscar neste mundo a medida suprema para a ação, impede-os de investir plenamente seus desejos numa vida de cidadão - desejos que, para uma minoria, são desejos de agir e, simultaneamente, de saber. No mundo moderno, os homens aceitam voluntariamente a servidão, e aqueles que exercem o mando são atraídos pela tirania. (LEFORT, 1999: 145)

Portanto, Maquiavel teria escolhido os antigos, em especial Roma, em razão de sua especificidade para a análise política. Especificidade, ou seja, uma história que explicita homens detentores de outra relação com o desejo, relação que possibilita o exercício da potência do corpo e da mente sem as amarras da servidão. Daí, talvez, a multiplicidade de exemplos advindos da história romana que mostram o exercício da virtù como força modificadora que não conhece o entrave de qualquer moral - ou regra de estofo jurídico - análoga à cristã, como mostro a seguir.

Ora, Maquiavel afirmara, no referido capítulo XV de $O$ príncipe, seu afastamento em face do modo de raciocinar dos outros. De fato, caso se considere como paradigma de análise do político A República, de Platão, entende-se a inovação maquiaveliana. Em vez de uma construção teórica perfeita, a ser alçada à condição de modelo a ser buscado, por que não ir ao que é, aos fatos mesmos, e daí apreender, se possível, o que de fato constitui a ação política e a fundação e manutenção dos corpos políticos? E, por que 
não, nessa linha argumentativa, entender o homem bom $^{11}$ a partir de sua relação com a circunstância política e não a partir da regra fixa jurídica ou mesmo moral, sobretudo a de fundo religioso-cristão?

Tem-se, assim, talvez pela primeira vez na história da filosofia, uma teoria política construída a partir da prática política tal qual esta se apresentou na história (LEFORT, 2000: 295-296). Ora, a história, isto é, os fatos mesmos submetidos a aguda análise, passam a ter local privilegiado nessa nova maneira de compreender o fenômeno político. Mas não se trata de narrar os fatos em busca apenas de uma fidelidade ao ocorrido. O ocorrido, isto é, a história, sobretudo a dos antigos, passa a ser a melhor fonte para o estabelecimento de um conjunto de constatações tendentes a ser "regras universais" da política. Entretanto, a universalidade de tais regras, dado o caráter mutável da história, isto é, dado o tempo de vida de todas as coisas (MAQUIAVEL, D, III, 1: 305), é sempre algo que tangencia a universalidade. É claro que, para Maquiavel, esse modo de proceder é algo muito mais consistente que a descrição de um dever ser modelar que jamais será alcançado. Nesse modelo de filosofia até então praticado, o que se tem é, para falar com Espinosa, não filosofia política, mas utopia ou sátira (ESPINOSA, 2009: 05) ${ }^{12}$.

11 Um contraponto à interpretação de Platão como construtor ingênuo da República (politeia) ideal deve ser feito. Platão não deixa de apontar, ainda que não desenvolva o tema ao limite, o caráter ambíguo do homem e os problemas advindos de sua natureza desejante. Conferir, por exemplo, as passagens 572 b-c, bem como 586 a-b do Livro IX de $A$ República. Apenas dois excertos, a seguir. De 586 a-b, nas palavras de Sócrates: “Assim, os indivíduos que não têm a experiência da sabedoria e da virtude (...) erram assim durante toda a vida. (...) À semelhança dos animais, de olhos sempre voltados para baixo, de cabeça inclinada para a terra e para a mesa, pastam na pastagem gorda e acasalam-se; e, para satisfazerem ainda mais seus apetites, escoicinham, batem-se com seus chifres e matam-se uns aos outros no furor de seu apetite insaciável (...). [Ao que Glauco diz]: Tu pareces um autêntico oráculo, Sócrates, ao descreveres a vida da maior parte dos homens.” E, em 572 a-b, de modo talvez mais claro, nas palavras de Sócrates: "O que queríamos constatar era que há em cada um de nós, mesmo nos que parecem totalmente disciplinados, uma espécie de desejos terríveis, selvagens, sem leis, e isso é posto em relevo pelos sonhos." Citações retiradas de PLATÃOO. A República. Coleção Os Pensadores. São Paulo: Nova Cultural, 2000. Cotejada com: PLATÃ̃. A República. Lisboa: Fundação Calouste Gulbenkian, 2010.

12 Trata-se do parágrafo de abertura do capítulo I do Tratado Político. Em suma, para Espinosa, na mesma linha argumentativa de Maquiavel, caso se entenda os homens e os corpos políticos como se gostaria que fossem, e não como são efetivamente, o que se faz é ou sátira ou utopia. Por quê? Quanto à sátira, esta consiste em desqualificar o comportamento real em comparação a um modelo virtuoso. Assim, a corrupção dos homens da igreja, por exemplo, é motivo de sátira em vista de um comportamento modelo que não é seguido, na vida cotidiana, por eles. Assim, com base em um modelo de homem e de corpo político ideais, nunca existentes, ri-se, com base no modelo, daquilo que existe efetivamente. Como o modelo nunca será alcançado, a ética e a filosofia política decorrentes dessa maneira de entender o campo da ação será, em alguns casos, um vituperar do comportamento que se vê no mundo real. Ou seja, sátira. O mesmo raciocínio vale para as filosofias políticas como utopias: constrói-se um modelo a ser alcançado e deixa-se de 


\section{Os homens bons, segundo Maquiavel: plenos de virtù}

Para a tradição humanista, o homem bom para a vida política não estava, eticamente, distante do homem bom em geral. Com efeito, seria bom o homem ou príncipe que tivesse virtù na vida política, sendo o conceito de virtù, para esta tradição, correlato à posse de virtudes como a liberalidade, a bondade, a sinceridade, a justiça ${ }^{13}$. Para Platão, como representante da tradição antiga, em A República, o caso exemplar de bom governante é o daquele que, pela educação dialética, alcança o entendimento da ideia de justiça e procura pôr em prática este saber.

Segundo Skinner (SKINNER, 2009: 151-152), para a tradição humanista, ser possuidor de virtù significa o respeito a duas ideias centrais. Uma: a virtù é entendida como a capacidade do príncipe para realizar seus mais nobres fins. Dois: a posse da virtù significava a posse do conjunto das principais virtudes. Maquiavel concordaria, segundo Skinner, que as metas do príncipe são a honra, a glória e a fama. Poder-se-ia acrescentar, com fundamento nos Discursos, a manutenção do Estado, do poder e a busca do interesse público. Entretanto, Maquiavel discorda - e eis sua inovação - da convicção reinante segundo a qual o meio mais seguro para a realização de tais fins é agir de modo convencionalmente virtuoso, isto é, a partir de uma tábua de valores, em geral advindos da moral cristã.

Duas teses são introduzidas nesse movimento, segundo o Skinner (SKINNER, 2009: 153). Primeira: nada seria tão importante quanto manter as aparências. Ou seja, em razão da circunstância política, é importante ao príncipe aparentar a boa virtude, sempre que possível, mesmo que não a possua. Segunda: muitas vezes é impossível ao príncipe (e ao homem bom, sendo o melhor príncipe, segundo Maquiavel, uma espécie de homem bom) portar-se de modo convencionalmente virtuoso. Qual a razão para isso? A razão é que, dadas algumas circunstâncias, portar-se de modo virtuoso, no sentido tradicional do termo, implica o fracasso e a ruína no campo político. $\mathrm{E}$, outra face desta moeda, alguns comportamentos que pelo metro tradicional seriam repugnantes, são os necessários para o momento político e para o sucesso da ação.

Assim, importa, sempre que possível, ao homem bom maquiaveliano (e, portanto, também ao seu príncipe), que aparente agir segundo a virtude tradicional. Ou seja, dentro desse metro, a circunstância política pode exigir

lado o mundo real, isto é, "a verdade efetiva da coisa", no dizer de Maquiavel. E assim a ética e a filosofia política se constroem como sátira ou como utopia, mas nunca como análise do que são efetivamente os homens, suas ações ou os corpos políticos que constroem.

${ }^{13}$ Vale lembrar que, para Maquiavel, não apenas os homens podem ter virtù, mas também o corpo político - o Estado -, o povo, os soldados. Ver o último parágrafo deste artigo para uma proposta de pesquisa, acerca do conceito de direito, a partir de Maquiavel.

A virtù e a regra: nota sobre Maquiavel - Luiz Carlos Montans Braga 
uma ação segundo o valor do cânone moral-cristão - por exemplo, a liberalidade. Entretanto, pode ocorrer de a circunstância política exigir a avareza, e o homem bom, ainda assim, conseguir aparentar liberalidade, mesmo tendo agido com avareza.

Entretanto, nem sempre as duas hipóteses do parágrafo acima são as mais virtuosas no sentido maquiaveliano. E então o homem bom passa a ser, paradoxalmente, aquele que age seja à revelia do valor dito virtuoso, seja sem conseguir aparentar agir segundo o valor virtuoso. E aí a ação segundo o "mau" valor é a melhor, a mais virtuosa, aquela típica do homem bom. Por quê? Porque a ação segundo o cânone rígido das virtudes morais (em geral a escala moral cristã) levaria ao mau resultado, à ruína. E, então, não seria a boa escolha. Afirma o autor (MAQUIAVEL, P, XV: 151): "Assim, é necessário a um príncipe que deseja conservar-se no poder, aprender a não ser bom, e sê-lo e não sê-lo conforme a necessidade."

Em suma, para Maquiavel, o homem bom é o que age com vistas ao melhor resultado político. E o melhor resultado político é aquele que traz ao agente glória, honra, fama e, simultaneamente, traz ao corpo político estabilidade e realização do bem público. Para que tudo isso seja alcançado, diz a história - isto é, "a verdade efetiva da coisa" -, a tábua de valores virtuosos não é, necessariamente, suficiente. Pode ocasionalmente ser, mas o que dirá qual a melhor ação ao agente é a necessidade política, a circunstância política (VALVERDE, 2012: 51-61) ${ }^{14}$. Esta exige criatividade máxima. Portanto, virtù (SKINNER, 2009: 159;203) ${ }^{15}$.

Nesta chave, no Livro Terceiro dos Discursos, o florentino lançará a seguinte tese: "A grande verdade é que todas as coisas do mundo têm seu tempo de vida" (MAQUIAVEL, D, III: 305). E, a partir dessa constatação acerca das coisas do mundo, dirá, sobre os corpos mistos (repúblicas ou seitas), que as alterações que venham a ocorrer neles devem levar ao seu princípio, a sua fundação. A volta ao princípio, diz Maquiavel, no caso das Repúblicas, será por evento externo ou interno. Os externos estão fora do controle do corpo político, daí serem perigosos (MAQUIAVEL, D, III, 1: 310). Quanto aos acontecimentos internos, escreve, "ou provêm de alguma lei que muitas vezes reveja a conduta dos homens que pertencem àquele corpo, ou de algum homem bom que surja entre eles e que, com seus exemplos e suas obras virtuosas, produza o mesmo efeito de uma

\footnotetext{
${ }^{14}$ Sobre este ponto, de uma perspectiva histórico-político-filosófica, afirma o autor: "Do ponto de vista político, a retomada do tema ciceroniano da vita activa trouxera consigo o lema virtù vince fortuna. Lema fortíssimo, porém de difícil objetivação política ao menos até o aparecimento da teoria política de Maquiavel, pois faltavam as condições históricas e políticas objetivas para a realização efetiva” (p. 53).

${ }^{15}$ Maquiavel, segundo Skinner, entende por virtù "todo conjunto de qualidades, sejam elas quais forem" (p. 159) e "não tem dúvidas de que a meta de manter a liberdade e segurança de uma República representa o valor mais elevado, e mesmo decisivo, da vida política. Por isso não hesita em concluir que não tem cabimento utilizar uma escala de valores cristã no exame dos assuntos políticos" (p. 203).
} 
ordenação" (MAQUIAVEL, D, III, 1: 307). Conclui, explicitando tanto o seu método, sobre o qual acima se falou, quanto sua aposta nos homens bons, no sentido que se deu ao termo na análise acima empreendida:

E, para demonstrar como as ações dos homens, individualmente, engrandeceram Roma e produziram naquela cidade muitos bons efeitos, passarei à narração e à consideração desses fatos, com o que se concluirão este terceiro livro e a última parte desta primeira Década. (...) E começarei por Bruto, pai da liberdade romana (MAQUIAVEL, D, III, 1: 310-311).

Se a deusa Fortuna é comparada a "um desses rios danosos que, quando se enfurecem, alagam as planícies, arruínam as árvores e os edifícios, (...) todos cedem ao seu ímpeto sem poder impedi-lo de modo algum" (MAQUIAVEL, P, XXV: 237), a virtù é a capacidade (do latim vis, de virilidade, potência ou força mental e corporal) criativa de conter a deusa Fortuna. Roma, ao que indica a profusão de exemplos e a escolha de sua história, via Tito Lívio, é fonte de fatos que mostram que a virtù pode vencer a fortuna. Os homens bons de Maquiavel são um caso de exercício ou manifestação da virtù. E não se trata de caso qualquer, como aponta o excerto citado. $\mathrm{O}$ homem bom, o que age com virtù, equivale à boa ordenação (boas leis) que muda o comportamento dos homens no corpo político e permite que este não se dissolva (MAQUIAVEL, D, III, 1: 307). Muita vez não bastam as leis, diria Maquiavel. E o direito, a boa ordenação, é substituída pela ação do homem com virtù que impede a ruína do corpo político.

Voltando à questão das máximas políticas: vê-se agora, com maior clareza, que não são fruto do imaginário do autor. É do ser histórico sob aguda análise que se retira a lição política. E o ser histórico exemplar, com muita ênfase nos Discursos, é Roma. Não há, assim, confecção de modelos de ação, de corpos políticos ideais, isto é, de utopias ou não-lugares, para usar o termo cunhado por Thomas More (MORE, 1993; MORE, 2003). Existe o exame da história.

Para o tema que aqui interessa, a saber, o dos homens bons, a passagem citada acima explicita a importância que Maquiavel dá a certos homens que agiram com excelência para o bem do corpo político.

Veja-se que a parte terceira dos Discursos consiste em "demonstrar como as ações dos homens, individualmente, engrandeceram Roma". O uso do advérbio individualmente discrimina a potência desses alguns em face dos demais. E tal potência resultou nos bons efeitos das ações de certos homens para Roma.

Que se tome, entre a infinidade de exemplos históricos de homens bons analisados por Maquiavel, aquele que se apresenta no capítulo 2 do livro III (MAQUIAVEL, D, III, 2: 311 e sgts). Isto, para que fique claro tanto o método maquiaveliano, quanto o modo de agir dos homens bons. 
Por que Júnio Bruto (Lúcio Júnio Bruto), anunciado no capítulo 1 dos Discursos como "pai da liberdade romana" (MAQUIAVEL, D, III, 1: 311), pode ser exemplo de um homem bom, isto é, pleno de virtù? Em primeiro lugar, em razão de ter sido o fundador do período republicano romano, findando a monarquia dos Tarquíneos. Para alcançar o objetivo, diz Maquiavel, usou da virtù em várias ações. Como sabia ser mais fraco que o rei, e estava com ele descontente, num primeiro momento simulou a amizade, para se tornar próximo. Isto porque não se pode combater alguém mais forte sem as forças para tal. Então o caminho é: "Mas, se para essa guerra aberta não bastarem suas forças, deverão com grande habilidade procurar torná-los seus amigos" (MAQUIAVEL, D, III, 2: 312). Tal familiaridade permite que se viva em segurança, afirma o autor, enquanto se aguarda a ocasião propícia para a confecção do intento. É claro, diz Maquiavel, que com isso correu o risco de quem se aproxima em demasia de um príncipe: "que a ruína dele [do príncipe] nos atinja" (MAQUIAVEL, D, III, 2: 312). Mas, nesse caso, esta era a única via. E Júnio Bruto, além de simular amizade em face do rei, simulou em duas outras ocasiões, ao menos. Em relação ao oráculo de Delfos, assim que ouviu uma voz dizer que teria o supremo império de Roma aquele que primeiro beijasse sua mãe, imediatamente simulou cair no chão e beijou a terra, mãe de $\operatorname{todos}^{16}$. Ou seja, teve virtù em face da profecia do oráculo. E o fez antes dos filhos do rei, que estavam com ele no oráculo. Fez algo similar em relação à violação de Lucrécia pelo filho do rei. Quando do suicídio de Lucrécia, em razão da violação feita pelo filho do rei, foi o primeiro a retirar a faca do ferimento e, ao mesmo tempo, arrancou dos presentes o juramento de que não tolerariam, no futuro, que alguém reinasse em Roma. Após a tomada do poder, como cônsul, e instalada a República, para mantê-la, matou os próprios filhos que queriam trazer de volta a monarquia (MAQUIAVEL, D, III, 3: 313 e sgts).

Para raciocinar anacronicamente, apenas como hipótese: se a escala de valores fosse a da moral cristã, ou de uma moral similar, ou mesmo as regras jurídicas instaladas na ocasião (o dever ser), uma série de violações a normas - e o medo da punição, aqui e além - seria o foco na análise das ações de Júnio Bruto. Por outra: Maquiavel focaria não o resultado republicano das ações, sua eficácia para a instauração e manutenção da república, mas as regras morais, religiosas e jurídicas violadas pelo homem bom dos exemplos acima. Porém, as ações tomadas a partir desse regramento fixo, com suas amarras, não poderiam mudar o futuro de Roma. Daí a importância de qualquer artifício que leve à ação correta no momento correto, visando ao bem público. No caso acima, o bem é a liberdade de Roma, com a instauração da República, regime ao mesmo tempo bom para o povo, que se libertou da tirania, e definidor da glória, da honra e da fama do seu fundador, homem bom porque cheio de virtù. Sem tal criatividade

\footnotetext{
${ }^{16}$ Conforme nota 9 da tradutora dos Discursos - ver referências bibliográficas.
} 
viril, por assim dizer, apenas as amarras da moral cristã - na hipótese anacrônica aqui delineada - seriam o critério da boa ação de Júnio Bruto. Ou seja, naquela circunstância política de Roma, descrita por Maquiavel, haveria apenas o fracasso, devidamente justificado em nome de uma salvação fora do reino deste mundo ${ }^{17}$.

Outro ponto, como conclusão em forma de esboço, a ser desdobrado em pesquisas futuras, é o que segue. Maquiavel e sua recusa do dever ser, moral ou jurídico, como chão para a construção do novo ou para o restabelecimento de uma ordem em dissolução poderia ser uma cunha teórica a ser introduzida no pensamento jurídico-político. Ou seja, suas teses de abertura para o possível como criação, de fissura do real por meio de regras a serem construídas segundo a conjuntura, não poderiam o aproximar de teorizações jurídicas de emancipação? Suas teses poderiam ser de valia (para os juristas do pensamento jurídico emancipatório) no sentido de possibilitar a leitura dos movimentos coletivos reivindicatórios como dotados, em muitos casos, da virtù própria aos homens bons. Ou seja, aquela que instaura o futuro ou resgata o corpo político em dissolução por meio da força criativa que, ao agir com metro novo, "viola" o ordenamento para instaurar o não pensado anteriormente. Uma espécie de construção do novo por um conceito de direito entendido como potência coletiva instauradora, ou seja, virtù dos movimentos reivindicatórios, hoje simplesmente criminalizados pelo pensamento jurídico dominante.

\section{Referências bibliográficas}

ARANOVICH, Patrícia Fontoura. Vocabulário de termos-chave de Maquiavel. In: MAQUIAVEL. Discursos sobre a primeira década de Tito Lívio. São Paulo: Companhia das Letras, 2007, pp. 457-471.

BERLIN, Isaiah. A originalidade de Maquiavel. In: HARDY, Henry e HAUSHEER, Roger (editores). Tradução de Rosaura Eichenberg. Estudos sobre a humanidade: uma antologia de ensaios. São Paulo: Companhia das Letras, 2002, pp. 299-348.

BIGNOTTO, Newton. As fronteiras da ética: Maquiavel. In: NOVAES, Adauto (org). Ética. São Paulo: Companhia das Letras/Secretaria Municipal de Cultura, 2003, pp. 113-125.

A antropologia negativa de Maquiavel. In: Analytica. Revista de Filosofia, Rio de Janeiro, Vol. 12, N.2, pp. 77-100, 2008.

\footnotetext{
${ }^{17}$ Termo inspirado no artigo do professor Antonio José Romera Valverde, que por sua vez se inspirou na obra de Alejo Carpentier (O Reino deste Mundo). Conferir: VALVERDE, A.J.R..Maquiavel: a natureza humana e o reino deste mundo. In: SGANZERLA, Anor; FALABRETTI, Ericson; VALVERDE, Antonio José Romera (orgs.). Natureza humana em movimento: ensaios de antropologia filosófica. São Paulo: Paulus, 2012, pp. 51-61.
} 
LEFORT, Claude. Maquiavel e a veritá effetuale. In: Desafios da Escrita Política. Tradução de Eliana de Melo Souza. São Paulo: Discurso editorial, 1999, pp. 141-177.

. Les formes de l'histoire: Essais d'anthropologie politique. Paris: Gallimard-folio, 2000.

ESPINOSA. Tratado Político. Tradução de Diogo Pires Aurélio e revisão de Homero Santiago. São Paulo: Martins Fontes, 2009.

LOGAN, George M.. Introduction. In: MORE, Thomas. Utopia. Cambridge: Cambridge University Press, 2003, pp. xi-xxix.

MAQUIAVEL. Discursos sobre a primeira década de Tito Lívio. São Paulo: Martins Fontes, 2007. Não consta o nome do tradutor (a).

O príncipe. Edição bilíngue. Tradução de José Antônio Martins.

São Paulo: Hedra, 2011.

MORE, Thomas. Utopia. Tradução de Jefferson Luiz Carmargo e Marcelo Brandão Cipolla. São Paulo: Martins Fontes, 1993.

. Utopia. Cambridge: Cambridge University Press, 2003.

PLATÃO. A república. Coleção Os Pensadores. São Paulo: Nova Cultural, 2000 .

. A república. Lisboa: Fundação Calouste Gulbenkian, 2010.

RIBEIRO, Renato Janine. A sociedade contra o social. São Paulo: Companhia das Letras, 2000.

SKINNER, Quentin. As fundações do pensamento político moderno. Tradução de Renato Janine Ribeiro (capítulo 1 a 11) e Laura Teixeira Motta (capítulo 12 em diante). São Paulo: Companhia das Letras, 2009.

VALVERDE, Antonio José Romera. Maquiavel: a natureza humana e o reino deste mundo. In: SGANZERLA, Anor; FALABRETTI, Ericson; VALVERDE, Antonio José Romera (orgs.). Natureza humana em movimento: ensaios de antropologia filosófica. São Paulo: Paulus, 2012, pp. $51-61$. 